\title{
Postharvest Changes in Internal Fruit Quality in Apples with Sunburn Browning
}

\author{
Larry E. Schrader ${ }^{2}$, Jianguang Zhang ${ }^{1}$, Jianshe Sun ${ }^{1}$, Jizhong $\mathbf{X u}^{1}$, Don C. Elfving, \\ and Cindy Kahn \\ Washington State University Tree Fruit Research \& Extension Center, 1100 N. Western Avenue, \\ Wenatchee, WA 98801
}

AdDitionAL INDEX WORDs. firmness, soluble solids concentration, titratable acidity, relative water concentration, cold storage, Malus $\times$ domestica

\begin{abstract}
Postharvest changes in flesh firmness, soluble solids concentration (SSC), and titratable acidity (TA) associated with increasing severity of sunburn browning of apples (Malus $\times$ domestica Borkh.) were investigated over time in regular atmosphere cold storage. In 2005, 'Gala' apples were harvested at maturity and sorted into five classes ranging from no sunburn (Sb-0) to severe sunburn browning (Sb-4). Flesh firmness, SSC, and TA were measured on flesh tissue beneath the sunburned area of the apples at harvest and at monthly intervals for 6 months. In 2006, a similar protocol was used for 'Gala', 'Golden Delicious', 'Jonagold', 'Granny Smith', and 'Fuji' apples, except that these fruit quality traits were determined at harvest and after 3 and 6 months in regular atmosphere cold storage. Flesh firmness and SSC increased, but TA decreased both years in all cultivars as sunburn severity increased from Sb-1 to $\mathrm{Sb}-4$. The patterns of higher firmness with more severe sunburn browning persisted during cold storage even though firmness in all classes of fruit decreased gradually with time in cold storage. The patterns of lower TA as severity of sunburn increased also persisted during cold storage, but TA declined more markedly in apples with more severe sunburn. The ratio of SSC to TA (SAR) increased as the severity of sunburn increased in all five cultivars. The SAR also increased dramatically from harvest to 3 and 6 months after harvest with ratios exceeding 200 in Sb-4 of some cultivars after 6 months storage. This occurred because TA declined very markedly as time in cold storage increased. Relative water concentration of tissue in sunburned areas of apples declined as the severity of sunburn increased, and helps to account for the higher SSC and firmness observed in sunburned apples.
\end{abstract}

Sunburn of apples is a physiological disorder caused by heat and/or light stress (Felicetti and Schrader, 2008a; Schrader et al., 2001, 2003a, 2004). Sunburn markedly increases cullage and results in large economic losses to growers (Schrader et al., 2003b). Sunburn of apples is a longstanding problem first described by Brooks and Fisher (1926). They inserted a thermometer into the cortex for temperature measurements and reported that exposure to the sun increased fruit surface temperatures (FST) of apples up to $14{ }^{\circ} \mathrm{C}$ on the sun-exposed side and often caused sunburn of those apples. More recent reports using thermocouples inserted into the fruit (Ferguson et al., 1998; Parchomchuk and Meheriuk, 1996) and attached to the fruit surface (Schrader et al., 2003b) indicated that FST could exceed air temperature by $15^{\circ} \mathrm{C}$ and sometimes by $17^{\circ} \mathrm{C}$, respectively. Schrader et al. (2003b) reported that maximum FST was highly correlated with the maximum daily air temperature $\left(\mathrm{r}=0.90^{* *}\right)$, the mean of maximum hourly air temperatures between 1100 and $1700 \mathrm{HR}\left(\mathrm{r}=0.88^{* *}\right)$, and mean solar radiation between 1100 and 1700 HR $\left(r=0.65^{* *}\right)$. However, mean wind velocity and mean relative humidity between 1100 and $1700 \mathrm{HR}$ were inversely correlated $(\mathrm{r}=$ $-0.24^{* *}$ and $-0.66^{* *}$, respectively) with maximum FST.

Received for publication 27 Oct. 2008. Accepted for publication 6 Dec. 2008. We are grateful for financial support from the Washington Tree Fruit Research Commission.

We also thank our colleague, Dr. Eugene Kupferman, for the use of his laboratory and equipment for the fruit quality analyses.

${ }^{1}$ Former Visiting Professor, now Professor, College of Horticulture, Agricultural University of Hebei, Baoding City, Hebei Province, 071001, China.

${ }^{2}$ Corresponding author. E-mail: schrader@wsu.edu.
Three distinct types of apple sunburn have been identified and characterized: photo-oxidative sunburn, sunburn necrosis, and sunburn browning. Photo-oxidative sunburn results from the sudden exposure of shaded peel to the visible range of solar radiation and can occur at FST below $31^{\circ} \mathrm{C}$. It is characterized by a photobleaching of the affected area with the possibility of brown, necrotic tissue appearing within the photobleached area (Felicetti and Schrader, 2008a). Schrader et al. (2001) described sunburn necrosis and sunburn browning, and later classified sunburn browning into four classes according to the extent of damage (Felicetti and Schrader, 2008b; Schrader et al., 2003a). The specific FST at which sunburn necrosis and browning occurred were determined experimentally on attached apples by Schrader et al. (2003b). Sunburn necrosis occurred when the FST reached $52 \pm 1{ }^{\circ} \mathrm{C}$ for only $10 \mathrm{~min}$, whereas sunburn browning varied with cultivars and occurred when FST of attached fully exposed apples was 46 to $49{ }^{\circ} \mathrm{C}$ for $1 \mathrm{~h}$ under environmental conditions prevailing in Wenatchee, WA. Induction of sunburn necrosis required only a high FST with no direct solar irradiance, whereas induction of sunburn browning required ultraviolet-B radiation and a high FST (Schrader et al., 2008). In Southern Hemisphere regions that have more ultraviolet-B radiation because of a thin ozone layer or the ozone hole, the threshold FST required for sunburn browning may be lower than the FST required under our conditions in the Pacific northwestern United States. This could explain the high incidence of sunburn browning observed in New Zealand where maximum air temperatures and FST are lower than those measured in Washington State.

Schrader et al. (2001) reported that the relative electrical conductivity (REC) for apples with sunburn necrosis was 
higher $(P \leq 0.05)$ than REC for fruit with no sunburn or with sunburn browning. Elevated REC in fruit with sunburn necrosis indicated that membrane integrity was destroyed, permitting electrolytes to leak freely. The REC for fruit with no sunburn and fruit with sunburn browning did not differ significantly, indicating that membrane integrity was unaffected by sunburn browning. These findings indicated that thermal death occurred with sunburn necrosis, but not with sunburn browning. Sunburn necrosis, but not sunburn browning, also caused serious changes in the cuticle and in epidermal and subepidermal tissues (Schrader et al., 2001).

Andrews and Johnson (1996) used electron microscopy to reveal that the wax cuticle on an apple's epidermis was dissipated by the intense sunlight associated with sunburn. They reported that cell walls thickened and lignified even before peel color changes were visible. However, they did not distinguish between sunburn browning and sunburn necrosis.

Apple trees are frequently exposed to air temperatures exceeding $35^{\circ} \mathrm{C}$ in several apple-growing regions of the world. Under these conditions, FST of sun-exposed apples can reach 45 to $50{ }^{\circ} \mathrm{C}$. Exposure of apples to these high FST required for sunburn browning raises questions about what effects these high temperatures have on internal fruit quality. Yet very little has been done to systematically investigate the effects of these high FST on internal fruit quality of apples.

Watkins et al. (1993) reported that sunburn may result in loss of fruit quality in 'Braeburn' apples, but provided no supporting data. Racskó et al. (2005a) reported that sunburn of apples increased flesh firmness, decreased water content, and increased soluble solids concentration. However, they did not indicate what type of sunburn they studied. They did indicate that plant cells suffering from sunburn died and that plant pathogens infected some fruit through the injured epidermal tissue, making the fruit unmarketable (Racskó et al., 2005b). Based on their description, it seems likely that Racskó et al. (2005a) studied sunburn necrosis or photo-oxidative sunburn, as necrosis (i.e., cell death) is a characteristic of photooxidative sunburn and sunburn necrosis, but not a characteristic of sunburn browning. We define sunburn browning as a peel disorder in which epidermal cells neither die nor incur damage that permit pathogens to infect the fruit. In contrast, sunburn necrosis results from thermal death, and can damage the apple epidermis so seriously that invasive pathogens can gain entry.

Although apples with slight to moderate sunburn browning are marketed, little is known about the impact sunburn browning has on apples as they move through storage, packing, and distribution. Hence, our objective was to investigate changes in internal fruit quality over time in regular atmosphere (RA) cold storage associated with increasing severity of sunburn browning of apples. We compared flesh firmness, soluble solids concentration (SSC), titratable acidity (TA), and the ratio of SSC to TA (SAR) in apples with different classes of sunburn damage that ranged from no sunburn (Sb-0) to severe sunburn browning (Sb-4).

\section{Materials and Methods}

SOURCES OF FRUIT FOR EXPERIMENTS. 'Gala' apples were harvested in 2005 and 2006 from the Columbia View research orchard at the Washington State University Tree Fruit Research and Extension Center (TFREC), Wenatchee, WA. In 2006, 'Jonagold' and 'Golden Delicious' apples were harvested from the TFREC orchard in Wenatchee; 'Granny Smith' apples were harvested from a commercial orchard near Orondo, WA; and 'Fuji' from a commercial orchard near Yakima, WA. Fruit were harvested when commercial maturity was attained (as determined by starch tests done by representatives from packinghouses). Apples were sorted as described earlier (Felicetti and Schrader, 2008b; Schrader et al., 2003a) into five classes ranging from $\mathrm{Sb}-0$ with no sunburn to $\mathrm{Sb}-4$ with severe sunburn browning. Fruit displaying symptoms of sunburn necrosis or photo-oxidative sunburn were not included in the samples collected. Fruit were then placed in conventional RA cold storage $\left(1^{\circ} \mathrm{C}\right)$.

Fruit QUALITy ANALYSES. Three internal fruit quality traits were determined: flesh firmness, SSC, and TA. In 2005, fruit were evaluated at harvest, and monthly from RA cold storage for 6 months. For sunburned apples, the epidermis $\left(\approx 4 \mathrm{~cm}^{2}\right)$ beneath the center of the sunburned area of each apple was removed to expose the cortex. For nonsunburned ( $\mathrm{Sb}-0)$ apples, the epidermis was removed from a similar area on the sunexposed side. Fifteen apples from each sunburn class were divided into three groups of five each. All three quality analyses were performed on each group. Flesh firmness under the sunburned area was measured on 15 apples individually for each class with a fruit texture analyzer (GÚSS Manufacturing, Strand, South Africa) with a 1.1-cm-diameter probe. Juice was expressed from the same 15 individual apples by inserting a stirring rod into cells surrounding the area depressed by the firmness probe (depth of $\approx 8 \mathrm{~mm}$ ); the expressed juice was placed on a digital hand-held pocket refractometer (PAL-1; Atago, Itabashi-ku, Japan) checked against a sucrose standard to determine the SSC. The mean for the five apples in each group was calculated for firmness and SSC, and was used as one replication for statistical analyses. For TA analyses, the same 15 apples were used, but only three extractions (using the same five apples per group as for firmness and SSC) per sunburn class were made with a juice blender. Five milliliters of juice were diluted to $25 \mathrm{~mL}$ with deionized water. This diluent was titrated to $\mathrm{pH} 8.2$ using a titrator (702 SM Titrino; Metrohm AG, Herisau, Switzerland) using 0.1 N KOH; TA is expressed as percentage of malic acid. Data for only the sun-exposed side of apples are shown, as sunburn had little effect on these fruit quality traits on the shaded side of fruit (data not shown). In 2006, apples were placed in RA cold storage at harvest. The quality traits were assayed at harvest, and after 3 and 6 months in RA storage using the same procedures.

Determination of Percentage OF WATER IN SUnburned APPLES. Relative water concentration (RWC) in fruit with different classes of sunburn was measured after harvest. A core ( $0.8 \mathrm{~cm}$ diameter and $1.5 \mathrm{~cm}$ long), including peel and cortex, was taken from the center of the sunburned area of each fruit with a cork borer. Samples for Sb-0 were taken from a similar sun-exposed area of the fruit. Two or three cores were placed in a weighed small glass cup for each replicate and were then weighed. There were three replicates for each sunburn class. Cups with cores were placed in an oven at $110{ }^{\circ} \mathrm{C}$ for $10 \mathrm{~min}$ and were then dried at $80{ }^{\circ} \mathrm{C}$ for $4 \mathrm{~d}$ until weight was constant. The RWC $(\%)=(\mathrm{F}-\mathrm{D}) / \mathrm{F} \times 100$ where $\mathrm{F}=$ fresh tissue weight and $\mathrm{D}=$ dry tissue weight.

EXPERIMENTAL DESIGN AND STATISTICAL ANALYSIS. The 2005 'Gala' trial was analyzed as a two-way factorial comparison of time in cold storage versus sunburn classes. The 2006 trial was analyzed as a three-way factorial of time in cold storage, 
sunburn classes, and cultivars. Analyses of variance and regression analyses were conducted on the three plot means (five fruit each) to assess the relation, if any, of fruit quality parameters to sunburn class, cultivar, and/or days after harvest as appropriate. Where interactions were significant, individual analyses were conducted on the appropriate classification variables as described for each experiment. Mean values were separated with the Waller-Duncan Bayesian k-ratio test $(P \leq$ 0.05 ) following a significant F-test. Analyses of regression assessed the presence of significant linear and curvilinear effects of time in cold storage (Elfving, 1990; Snedecor and Cochran, 1980). Statistical analyses were performed using the General Linear Models procedure of SAS (version 8.02; SAS Institute, Cary, NC).

\section{Results}

2005 STUDY ON 'GALA' APPLE. In terms of flesh firmness and $\mathrm{SSC}$, no interactions between time in cold storage and sunburn class were found for these two quality traits. Hence, both traits were analyzed by regression for time in cold storage (values for each storage date in Table 1 are the mean of all sunburn classes for that date) and by analysis of variance plus mean separation for sunburn classes (values for each sunburn class in Table 1 are the mean of all cold-storage dates for that class). Flesh firmness decreased with increased time in cold storage (Table 1). The rate of change in firmness with time in storage decreased as storage time increased (quadratic and cubic effects). In contrast, SSC increased after harvest, peaking around $100 \mathrm{~d}$ after harvest, and then slightly declined (quadratic effect describes curvilinear response).

Table 1. Relationship of time after harvest (days in cold storage) and sunburn class to fruit flesh firmness and soluble solids concentration of 'Gala' apples in 2005.

\begin{tabular}{|c|c|c|}
\hline $\begin{array}{l}\text { Time after } \\
\text { harvest }(\mathrm{d})^{\mathrm{Z}}\end{array}$ & Flesh firmness $(\mathrm{N})$ & $\begin{array}{c}\text { Soluble solids } \\
\text { concentration (\%) }\end{array}$ \\
\hline 0 & 91.1 & 11.4 \\
\hline 36 & 85.3 & 11.7 \\
\hline 67 & 74 & 12.3 \\
\hline 110 & 62.7 & 12.4 \\
\hline 129 & 61.7 & 11.7 \\
\hline 159 & 59.8 & 12.0 \\
\hline \multirow[t]{2}{*}{188} & 58.8 & 11.6 \\
\hline & Significance & \\
\hline Linear & $* * * *$ & $* * * *$ \\
\hline Quadratic & $* * * *$ & $* * * *$ \\
\hline Cubic & $* *$ & NS \\
\hline Model $\mathrm{R}^{2}$ & 0.92 & 0.65 \\
\hline Sunburn class ${ }^{y}$ & Flesh firmness $(\mathrm{N})$ & $\begin{array}{c}\text { Soluble solids } \\
\text { concentration }(\%)\end{array}$ \\
\hline $\mathrm{Sb}-0$ & $61.7 \mathrm{~d}$ & $11.2 \mathrm{e}$ \\
\hline $\mathrm{Sb}-1$ & $66.6 \mathrm{c}$ & $11.6 \mathrm{~d}$ \\
\hline $\mathrm{Sb}-2$ & $71.5 \mathrm{~b}$ & $11.9 \mathrm{c}$ \\
\hline $\mathrm{Sb}-3$ & $73.5 \mathrm{~b}$ & $12.2 \mathrm{~b}$ \\
\hline $\mathrm{Sb}-4$ & $79.4 \mathrm{a}$ & $12.5 \mathrm{a}$ \\
\hline Interaction $^{z}$ & NS & NS \\
\hline
\end{tabular}

Significance: NS, not significant; $* * P \leq 0.01 ; * * * * P \leq 0.0001$.

${ }^{\mathrm{y}}$ Mean separation in columns by Waller-Duncan Bayesian k-ratio test $(P \leq 0.05)$.
Flesh firmness and SSC were greater with increased sunburn severity (Table 1). Both traits were higher in Sb-4 than in all other sunburn classes, and $\mathrm{Sb}-0$ was lower than all other classes for both traits.

2005 STUdY ON 'GALA' APPLE: TA AND RATIO OF SSC to TA. For TA and SAR, a significant interaction $(P \leq 0.05)$ was observed between sunburn classes and time in cold storage. Hence, we analyzed these parameters across sunburn classes separately for each of the seven cold-storage times. The TA generally decreased as the severity of sunburn browning increased (Fig. 1A). As time in cold storage increased, TA decreased in all sunburn classes and the differences among the different classes of sunburn increased. At harvest, Sb-0, Sb-1, and Sb-2 were higher than Sb-4 in TA. At 36 d, TA was higher in $\mathrm{Sb}-0$ and $\mathrm{Sb}-1$ than other classes. In all subsequent evaluations, TA in Sb-0 was higher than in all other classes. Beginning at day 67, Sb-4 was lower in TA than Sb-0, Sb-1, and Sb-2.

The SAR was higher at harvest in Sb-4 than in Sb-0 and Sb-1 (Fig. 1B). At all subsequent evaluations, SAR for Sb-4 was higher than for all other sunburn classes, and SAR for Sb-2 and $\mathrm{Sb}-3$ was usually higher than for Sb-0 and Sb-1.

2006 STUDY ON FIVE APPLE CULTIVARS. There were significant interactions $(P \leq 0.05)$ among all combinations of sunburn class, cultivar, and storage time for each fruit quality parameter
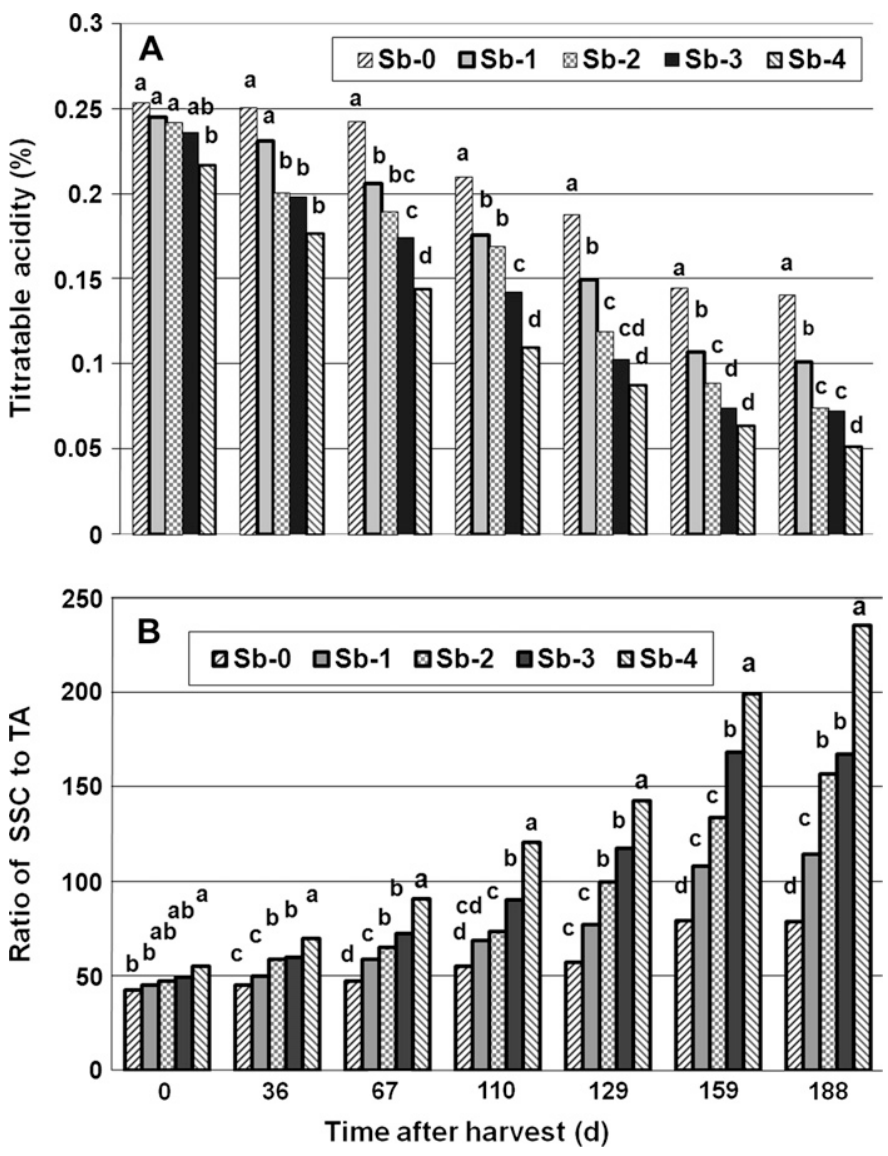

Fig. 1. Comparison of titratable acidity (A) and the ratio of soluble solids concentration (SSC) to titratable acidity (TA) (B) in 'Gala' apples with different classes of sunburn browning in 2005. Evaluations were done at harvest and at intervals up to 6 months in cold storage; $\mathrm{Sb}-0=$ no sunburn, $\mathrm{Sb}-1$ to $\mathrm{Sb}-4$ = increasing severity of sunburn browning. 
measured. Hence, one-way analyses of variance were run on each cultivar separately for each storage time.

Flesh FIRMness. Flesh firmness was greater in all five cultivars as sunburn browning severity increased (Fig. 2), but specific relationships of firmness among sunburn classes were not identical among cultivars. Firmness of all fruit decreased over time in cold storage, but the trend of higher firmness in higher classes of sunburn was preserved.

In 'Gala', firmness was higher in Sb-4 than in Sb-0 and Sb-1 at harvest (Fig. 2A), and after 6 months (Fig. 2C) of cold storage. With 'Jonagold', Sb-4 firmness was usually higher than
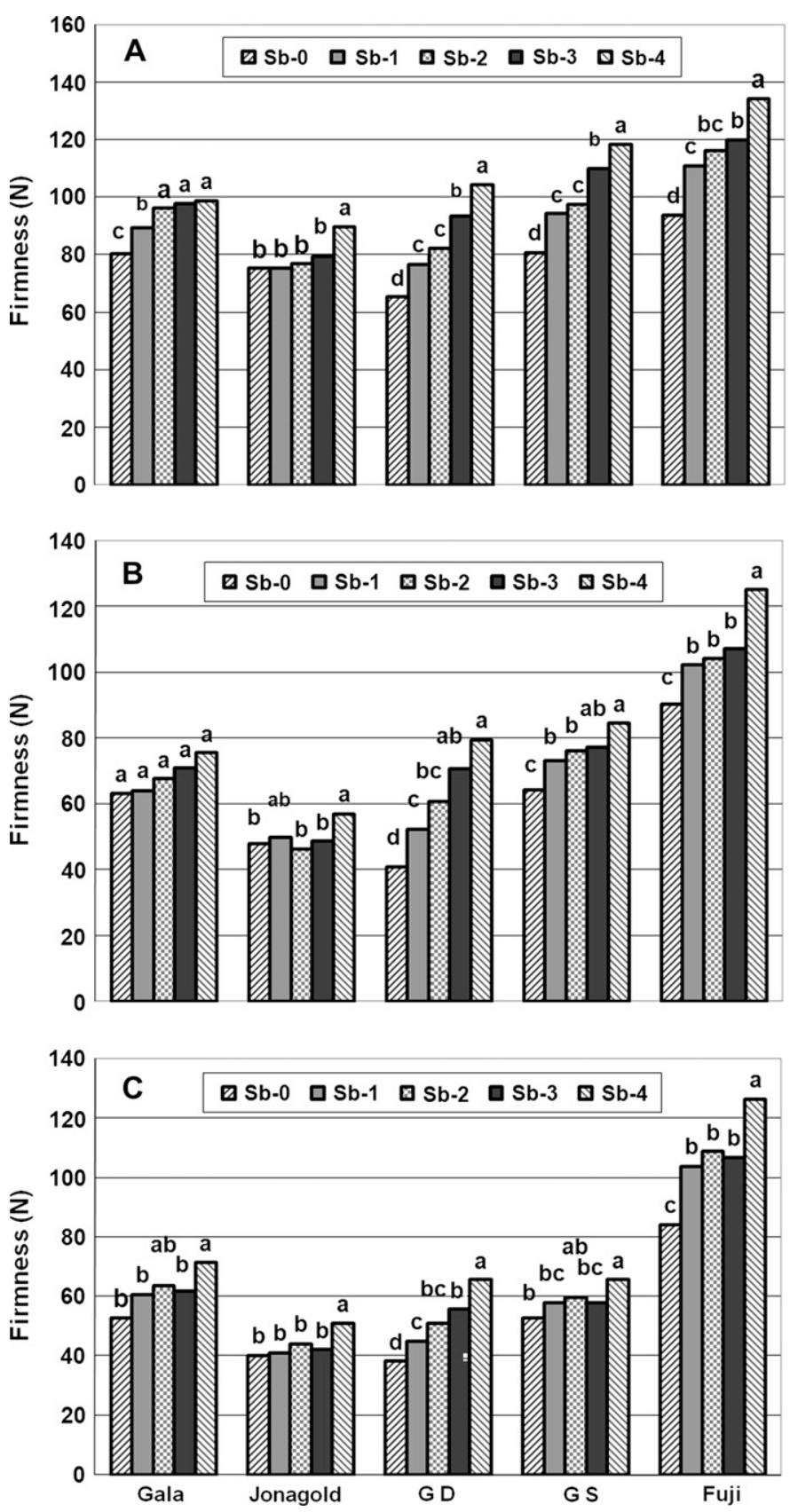

Fig. 2. Comparison of flesh firmness at harvest (A), after 3 months (B), and at 6 months of cold storage $(\mathbf{C})$ in five apple cultivars with different classes of sunburn browning in 2006; JON = 'Jonagold', GD = 'Golden Delicious', GS = 'Granny Smith'. Sb-0 = no sunburn, Sb-1 to Sb-4 = increasing severity of sunburn browning. all other sunburn classes, and Sb-0, Sb-1, Sb-2, and Sb-3 were not different. 'Golden Delicious' Sb-4 firmness was usually higher than that of all other classes. Firmness of Sb-0 was lower than in all other sunburn classes; Sb-1 was firmer than Sb-0, and Sb-3 was firmer than Sb-1. With 'Granny Smith', firmness of $\mathrm{Sb}-4$ was higher than that of Sb-0 and Sb-1. At harvest, Sb-4 was higher in firmness than all other classes. In 'Fuji', firmness was higher in Sb-4 than in all other classes. Firmness of Sb0 was lower than in the other classes, and classes Sb-1 to Sb-3 usually were not different.

SSC. The SSC in fruit was generally greater with increasing sunburn browning severity in all five cultivars (Fig. 3), again with differences among sunburn classes in different cultivars. This trend persisted from harvest to 6 months after harvest.

In 'Gala', SSC was higher in Sb-4 than in Sb-0 (Fig. 3). With 'Jonagold', SSC was higher in Sb-4 than in Sb-0 and Sb-1 at harvest and after 6 months of storage. In 'Golden Delicious', $\mathrm{SSC}$ was higher in Sb-4 than in Sb-0, Sb-1, and Sb-2; Sb-0 was lower than in all other classes and Sb-1 was lower than Sb-3. In 'Granny Smith', SSC in Sb-0 was usually lower than in other classes. With 'Fuji', SSC was lowest in Sb-0 and usually highest in Sb-4.

TA. The TA was generally lower in all five cultivars with increasing severity of sunburn browning (Fig. 4), again with differences among sunburn classes in different cultivars. As time in cold storage increased, TA decreased for each cultivar. The decrease in TA was largest between harvest and 3 months storage (Fig. 4, A and B).

In 'Gala', TA in nonsunburned fruit (Sb-0) was higher than in sunburned fruit; TA was usually higher in Sb-1 than in other classes of sunburn. With 'Jonagold', TA was higher in class $\mathrm{Sb}-0$ than in Sb-3 and Sb-4. With 'Golden Delicious', TA was higher in Sb-0 than in Sb-2, Sb-3, and Sb-4. In 'Granny Smith', TA displayed much higher values than the other cultivars; Sb-0 and $\mathrm{Sb}-1$ tended to be higher than Sb-2, Sb-3, and Sb-4. With 'Fuji', Sb-0 had higher TA than the other sunburn classes. At harvest and at 3 months after harvest, TA was higher in Sb-1 and $\mathrm{Sb}-2$ than in Sb-3 and Sb-4.

RAtio of SSC to TA. The SAR for all cultivars was lowest at harvest for each sunburn browning class (Fig. 5A), again with differences among sunburn classes in different cultivars. SAR increased markedly for all cultivars after 3 months of cold storage (Fig. 5B). The SAR at harvest and after 3 months increased in all cultivars as sunburn severity increased. After 6 months of cold storage, SAR for sunburned 'Golden Delicious', 'Granny Smith', and 'Fuji' was usually different from Sb-0, but differences among the other classes were small (Fig. 5C). The SAR values for 'Granny Smith' were lower than for other cultivars due to much higher TA concentrations for 'Granny Smith' at all sampling dates.

RWC. The RWC of cores taken from the sunburned areas of four cultivars was examined in a separate experiment. With all four cultivars studied, the RWC decreased as severity of sunburn increased (Fig. 6), again with differences among sunburn classes in different cultivars. In general, the percentage of dry matter increased in cores from apples with more severe sunburn damage.

\section{Discussion}

As the severity of sunburn browning increased in 2005 and 2006, flesh firmness, SAR, and SSC increased, but TA 

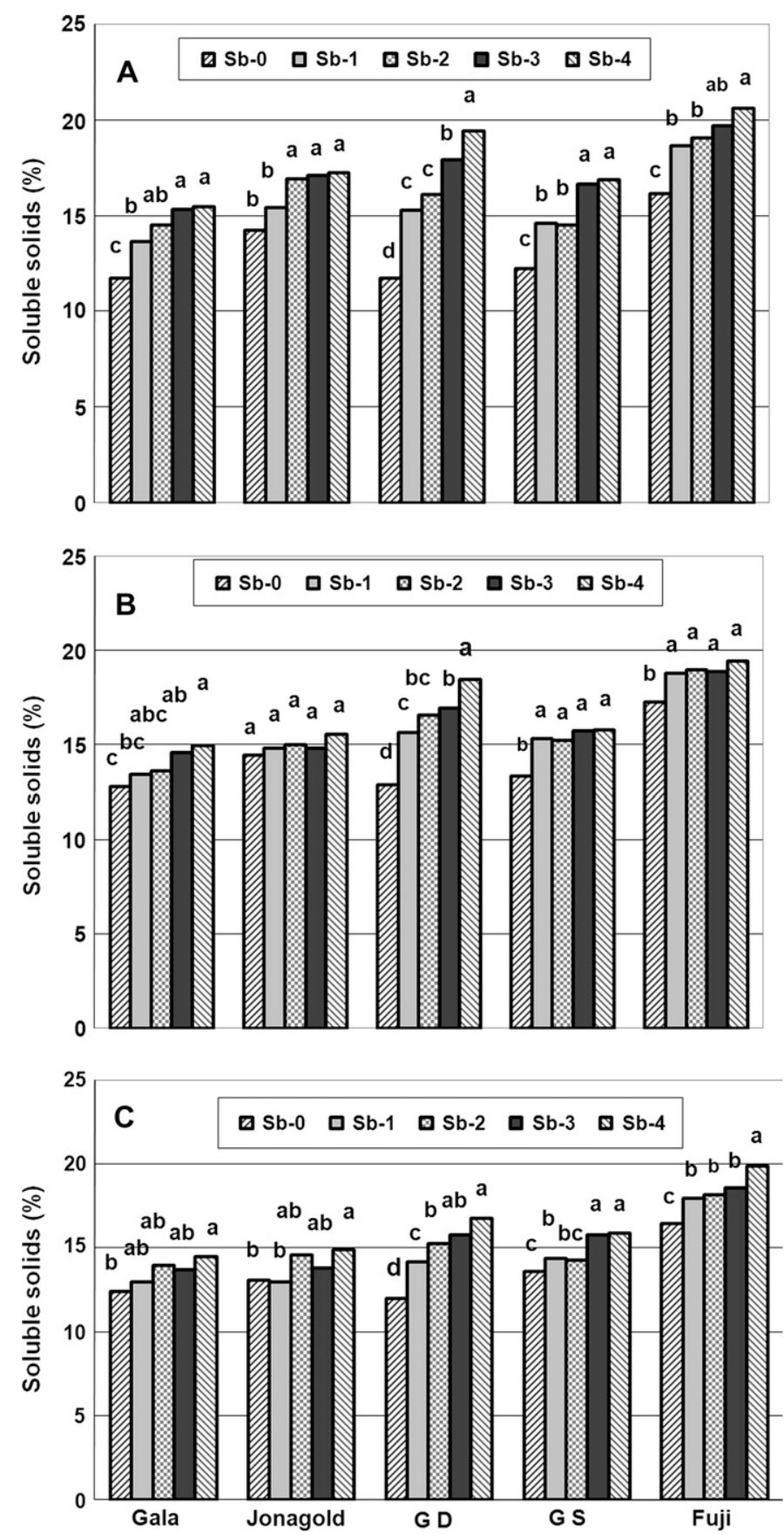

Fig. 3. Comparison of soluble solids concentration at harvest (A), after 3 months (B), and at 6 months of cold storage (C) in five apple cultivars with different classes of sunburn browning in 2006; JON = 'Jonagold', GD = 'Golden Delicious', GS = 'Granny Smith'. Sb-0 = no sunburn, Sb-1 to Sb-4 = increasing severity of sunburn browning.

decreased. These trends were evident at harvest and persisted in fruit tested after 6 months of RA cold storage. The origin of the firmness and SSC changes in relation to sunburn browning is unknown. However, the reduction in RWC (i.e., increased percentage of dry matter) observed in the affected tissues helps account for the higher SSC in sunburned apples. Woolf and Ferguson (2000) suggested that increased firmness could be due to differing cell wall composition, cell number, or cell turgor properties on the sun-exposed side of apples
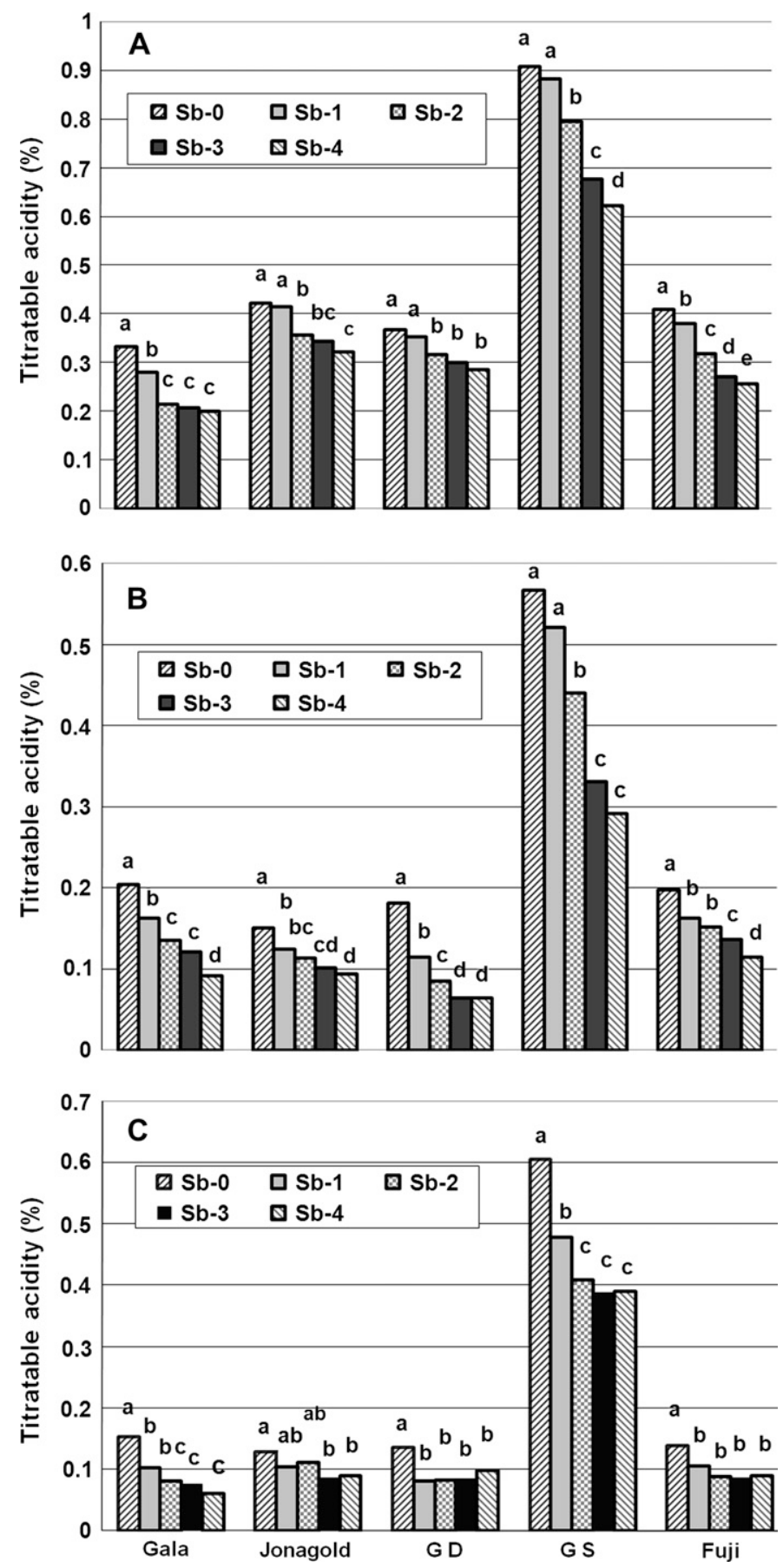

Fig. 4. Comparison of titratable acidity at harvest (A), after 3 months (B), and at 6 months of cold storage $(\mathbf{C})$ in five apple cultivars with different classes of sunburn browning in 2006; JON = 'Jonagold', GD = 'Golden Delicious', GS = 'Granny Smith'. Sb-0 = no sunburn, Sb-1 to Sb-4 = increasing severity of sunburn browning.

Our results are consistent with the earlier report of Racskó et al. (2005a) that firmness and SSC were higher in sunburned apples (cv. Idared) grown in Hungary. They reported that water content of sunburned tissue decreased, and the tissue got harder. They attributed the observed increase in SSC and firmness to this water loss. Because Racskó et al. indicated that sunburned plant cells in their study mainly perished, we believe they studied effects of sunburn necrosis, or possibly photo-oxidative sunburn, rather than sunburn browning. 

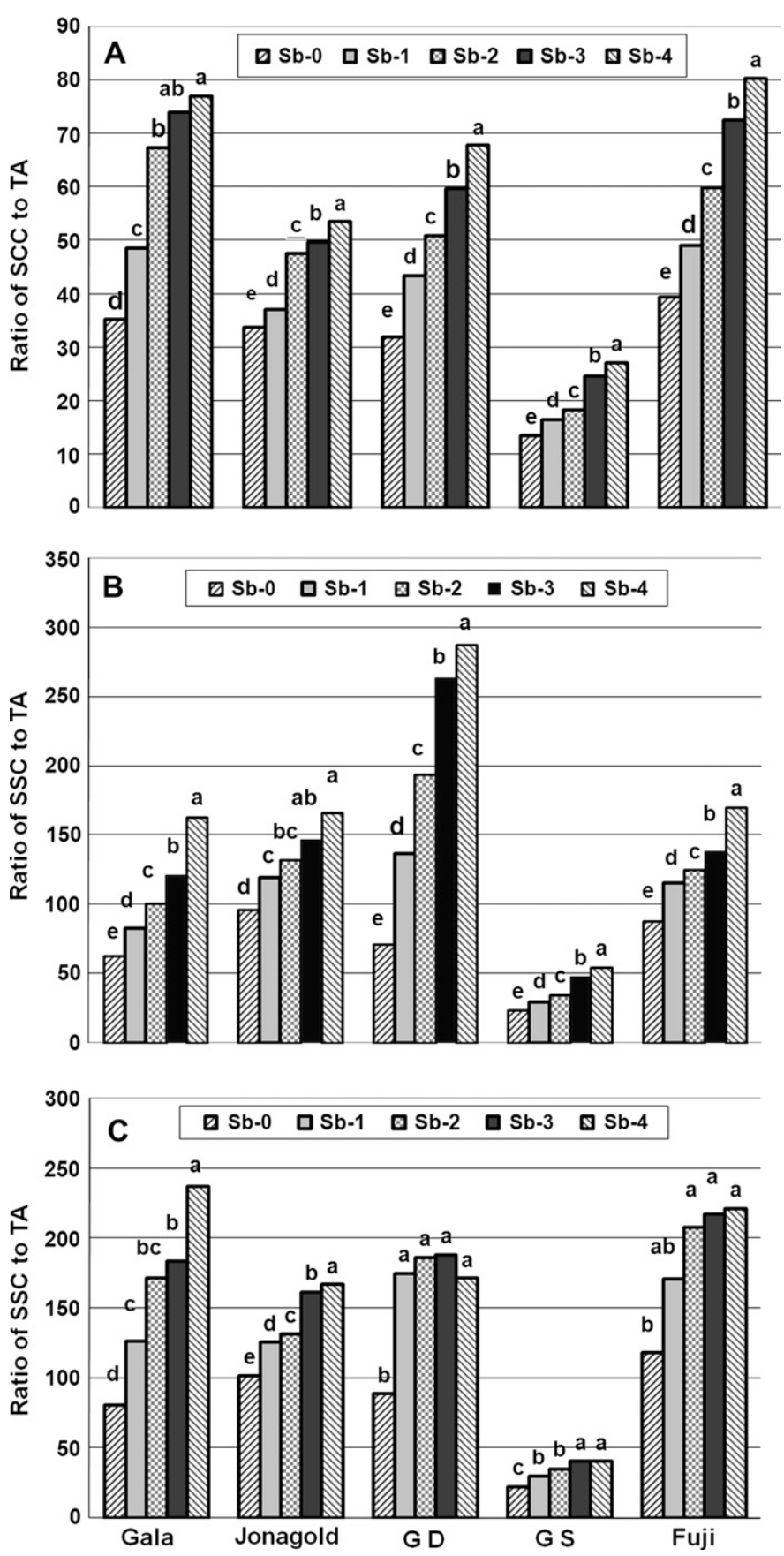

Fig. 5. Comparison of the ratio of soluble solids concentration (SSC) to titratable acidity (TA) at harvest (A), after 3 months (B), and at 6 months of cold storage $(\mathbf{C})$ in five apple cultivars with different classes of sunburn browning in 2006; JON = 'Jonagold', GD = 'Golden Delicious', GS = 'Granny Smith' (2006). Sb-0 = no sunburn, Sb-1 to Sb-4 = increasing severity of sunburn browning.

Although we are unaware of previous reports on the effects of sunburn browning on apple fruit quality, several investigators have reported the effects of sun exposure on apple fruit firmness and other quality traits in nonsunburned fruit. Klein et al. (2001) reported that the sun-exposed side of apples was firmer and had higher SSC than the shaded side. TA was similar on both sides of their fruit at harvest. Moisture content of shaded fruit at harvest (86.4\%) was significantly higher $(P \leq$ $0.05)$ than in sun-exposed fruit with only $84.1 \%$ moisture.

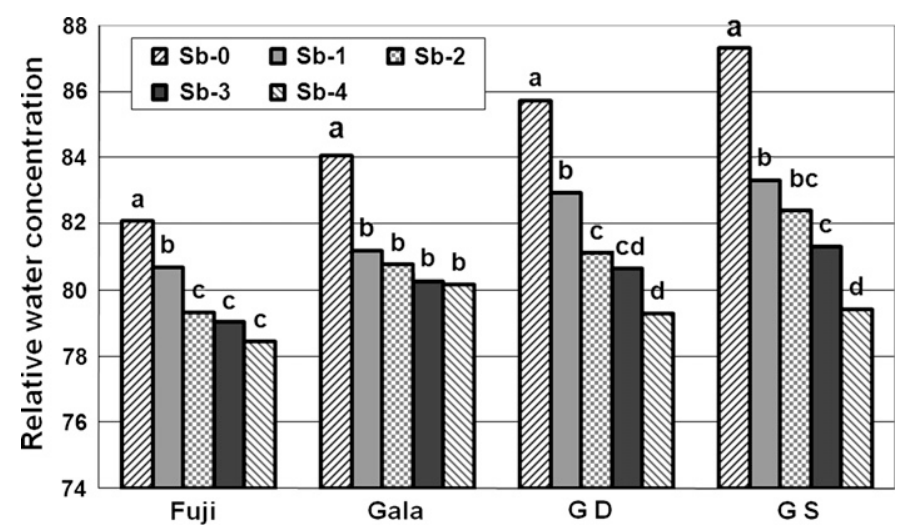

Fig. 6. Relative water concentration in different classes of sunburned fruit for four apple cultivars in 2007; GD = 'Golden Delicious', GS = 'Granny Smith'. $\mathrm{Sb}-0=$ no sunburn, $\mathrm{Sb}-1$ to $\mathrm{Sb}-4=$ increasing severity of sunburn browning.

Ferguson et al. (1999) also reported that the sun-exposed side of apples had higher firmness than the shaded side. Dussi et al. (2005) in Argentina reported that use of 55\% density shade nets over 'Fuji' trees decreased PAR, fruit color, SSC, and flesh firmness. Nilsson and Gustavsson (2007) reported that during maturation on the tree, 'Aroma' apples located on the outside of the canopy had a higher content of dry matter, SSC, and soluble sugars but a somewhat lower TA than fruit located on the inside of the canopy. Tustin et al. (1988) also found that fruit harvested from the inner canopy had lower SSC than fruit from outer branches.

Brooks and Fisher (1926) reported that sun-exposed sides of apple fruit had higher sap concentrations (i.e., lower $\psi_{\mathrm{S}}$ ) than shaded sides of the same fruit. They also reported that juice from slightly sunburned apples had even higher sap concentrations. Although SSC was not measured, their findings imply that SSC would be higher in sunburned apples.

$\mathrm{Wu}$ et al. (2007) reported sugar/acid ratios of nonsunburned fruit for eight apple cultivars grown in China. These included 'Granny Smith', 'Fuji', 'Golden Delicious', and 'Jonagold'. 'Granny Smith' had the highest levels of total acids and the lowest sugar/acid ratio of the eight apple cultivars. These findings are consistent with our results (Figs. 4 and 5).

The marked decrease in TA observed in apples with sunburn damage would be expected to affect acid taste, as Harker et al. (2002) reported that acid taste may be predicted on the basis of TA. The large changes in TA and the SAR observed in our study would be expected to dramatically affect the acid taste of sunburned apples, especially after 3 or 6 months of cold storage. Further research is needed to conduct sensory evaluations of apples with sunburn browning.

Is there a causal relationship between sunburn browning and the observed changes in fruit quality? Sunburn browning occurs when attached apples are exposed to high solar irradiance and a cultivar-dependent FST that is above a certain threshold temperature $\left(46-49^{\circ} \mathrm{C}\right)$. High light and high FST can directly affect many metabolic processes. Sunburn and changes in fruit quality may in fact represent fruit responses to the stresses imposed by excess temperature and solar irradiance. For example, high peel temperatures would likely increase respiratory losses and accelerate or interfere with many other metabolic reactions. Warmund et al. (2007) bagged attached apples for $5 \mathrm{~d}$ before harvest, and reported that the respiration 
rate of the bagged apples more than doubled with a 3 to $4{ }^{\circ} \mathrm{C}$ increase in air temperature. Exposure of fruit to high temperatures can also hasten maturity and can lead to earlier degradation of starch. In fact, a recent study (L.E. Schrader, unpublished data) showed that starch clears more rapidly in apples as severity of sunburn browning increases from Sb-1 to $\mathrm{Sb}-4$.

The decreasing TA concentrations observed in sunburned apples at harvest and during cold storage may be due to what Ferguson et al. (1999) referred to as a "postharvest response associated with prior high temperature or exposure history." Woolf and Ferguson (2000) discussed mechanisms of high temperature effects on postharvest responses, including the role of heat shock proteins, membrane damage, and skin characteristics. They proposed that differences in exposure of fruit on the tree may be responsible for much of the wide variation commonly found in fruit with regard to at-harvest quality, ripening, and postharvest behavior. They noted that diurnal temperature fluctuations of up to $35^{\circ} \mathrm{C}$ occur in sun-exposed apples, and must require impressive homeostatic control of cell metabolism.

High solar irradiance can lead to production of reactive oxygen species (ROS) and singlet oxygen. Triantaphylidés et al. (2008) recently reported that ROS can directly provoke cellular damage by rapidly oxidizing cellular components, including lipids. Proteins, pigments, and nucleic acids also can be damaged by ROS. Singlet oxygen is very reactive and oxidizes amino acids and lipids found in the cell. Changes effected by ROS and singlet oxygen may affect fruit quality. Hence, it seems quite plausible that changes in fruit quality may not be directly attributed to sunburn browning in apples; rather, the occurrence of all of these changes may reflect the underlying changes in fruit induced under specific light/temperature conditions.

It is common practice for apple packers to combine classes $\mathrm{Sb}-0$ and Sb-1 into their premium grade (e.g., extra fancy) for marketing. Yet significant changes in firmness, SSC, and TA were frequently observed between $\mathrm{Sb}-0$ and $\mathrm{Sb}-1$ in this study. At this time, the practical impact of these observed differences in firmness, SSC, and TA has not been established, but it may not be a sound practice to combine $\mathrm{Sb}-1$ with $\mathrm{Sb}-0$ apples in the premium grade for long-term cold storage. Further studies are needed to establish what impact the fruit quality changes reported in this article have on taste, aroma, storage life, and other aspects of fruit quality. In addition, the variability in the response of individual cultivars to sunburn suggests that further research is needed to characterize the storability and poststorage quality of specific cultivars in relation to sunburn severity.

\section{Conclusions}

Although sunburn browning has generally been thought of as a disorder affecting only the appearance of an apple's peel, these studies show that undesirable changes in selected internal fruit quality traits are associated with even slight or moderate sunburn browning of five apple cultivars. Flesh firmness and SSC increased as the severity of sunburn browning increased; however, RWC and TA decreased markedly with more severe sunburn damage. Although firmness decreased over time in cold storage, TA decreased substantially more than did firmness. This marked decrease in TA caused the SAR to increase dramatically as time in storage was extended, and greatly affected the SAR of the apples.

\section{Literature Cited}

Andrews, P.K. and J.R. Johnson. 1996. Physiology of sunburn development in apples. Good Fruit Grower 47:33-36.

Brooks, C. and D.F. Fisher. 1926. Some high-temperature effects in apples: Contrasts in the two sides of an apple. J. Agr. Res. 32:1-16. Dussi, M.C., G. Giardina, D. Sosa, R.G. Junyent, A. Zecca, and P. Reeb. 2005. Shade nets effect on canopy light distribution and quality of fruit and spur leaf on apple cv. 'Fuji'. Span. J. Agric. Res. 3:253260.

Elfving, D.C. 1990. Growth and productivity of 'Empire' apple trees following a single heading-back pruning treatment. HortScience 25:908-910.

Felicetti, D.A. and L.E. Schrader. 2008a. Photooxidative sunburn of apples: Characterization of a third type of apple sunburn. Int. J. Fruit Sci. 8(3/4):160-172.

Felicetti, D.A. and L.E. Schrader. 2008b. Changes in pigment concentrations associated with the degree of sunburn browning of 'Fuji' apple. J. Amer. Soc. Hort. Sci. 133:27-34.

Ferguson, I.B., W. Snelgar, J.H. Bowen, and A.B. Woolf. 1999. Preharvest field heat and postharvest fruit response. Acta Hort. 485:149-154.

Ferguson, I.B., W. Snelgar, M. Lay-Yee, C.B. Watkins, and J.H. Bowen. 1998. Expression of heat shock protein genes in apple fruit in the field. Aust. J. Plant Physiol. 25:155-163.

Harker, F.R., K.B. Marsh, H. Young, S.H. Murray, F.A. Gunson, and S.B. Walker. 2002. Sensory interpretation of instrumental measurements 2: Sweet and acid taste of apple fruit. Postharvest Biol. Technol. 24:241-250.

Klein, J.D., L. Dong, H.-W. Zhou, and S. Lurie. 2001. Ripeness of shaded and sun-exposed apples (Malus domestica). Acta Hort. 553:95-98.

Nilsson, T. and K.E. Gustavsson. 2007. Postharvest physiology of 'Aroma' apples in relation to position on the tree. Postharvest Biol. Technol. 43:36-46.

Parchomchuk, P. and M. Meheriuk. 1996. Orchard cooling with pulsed overtree irrigation to prevent solar injury and improve fruit quality of 'Jonagold' apples. HortScience 31:802-804.

Racskó, J., S. Thurzó, Z. Szabó, and J. Nyéki. 2005b. Schadwirkung des Sonnenbrands auf das Gewebe des Apfels (Malus domestica Borkh.) (in German with English abstract). Gesunde Pflanzen 57:47-52.

Racskó, J., Z. Szabó, and J. Nyéki. 2005a. Importance of the supraoptimal radiance supply and sunburn effects on apple fruit quality. Proc. 8th Hungarian Congr. Plant Physiol. and 6th Hungarian Conf. Photosyn. Acta Biologica Szegediensis 49:111-114.

Schrader, L.E., J. Sun, D. Felicetti, J.-H. Seo, L. Jedlow, and J. Zhang. 2003a. Stress-induced disorders: Effects on apple fruit quality. 21 Nov. 2008. <http://postharvest.tfrec.wsu.edu/PC2004E.pdf $>$.

Schrader, L.E., J. Sun, J. Zhang, and J.-H. Seo. 2004. Fruit skin disorders. 21 Nov. 2008. <http://postharvest.tfrec.wsu.edu/PC2003A. pdf $>$.

Schrader, L.E., J. Sun, J. Zhang, D. Felicetti, and J. Tian. 2008. Heatand light-induced apple skin disorders: Causes and prevention. Acta Hort. 772:51-58.

Schrader, L.E., J. Zhang, and J. Sunday. 2003b. Environmental stresses that cause sunburn of apple. Acta Hort. 618:397-405.

Schrader, L.E., J. Zhang, and W.K. Duplaga. 2001. Two types of sunburn in apple caused by high fruit surface (peel) temperature. 21 Nov. 2008. Plant Health Prog. doi: 10.1094/PHP-2001-1004-01-RS. Snedecor, G.W. and W.G. Cochran. 1980. Statistical methods, 7th ed. Iowa State University Press, Ames.

Triantaphylidés, C., M. Krischke, F.A. Hoeberichts, B. Ksas, G. Gresser, M. Havaux, F. Van Breusegem, and M.J. Mueller. 2008. Singlet oxygen is the major reactive oxygen species involved in photooxidative damage to plants. Plant Physiol. 148:960-968. 
Tustin, D.S., P.M. Hirst, and I.J. Warrington. 1988. Influence of orientation and position of fruiting laterals on canopy light penetration, yield, and fruit quality of 'Granny Smith' apple. J. Amer. Soc. Hort. Sci. 113:693-699.

Warmund, M.R., C. Starbuck, and S. Kadir. 2007. Changes in fruit quality parameters of 'Jonathan Rasa' and 'Delicious Flanagan' apples in response to elevated temperatures. Trans. Kans. Acad. Sci. 110:259-267.
Watkins, C., R. Harker, P. Brookfield, and S. Tustin. 1993. Maturity of Royal Gala, Braeburn and Fuji: The New Zealand experience. Proc. Washington Tree Fruit Postharvest Conf. 9:16-19.

Woolf, A.B. and I.B. Ferguson. 2000. Postharvest responses to high fruit temperatures in the field. Postharvest Biol. Technol. 21:7-20.

Wu, J., H. Gao, L. Zhao, X. Liao, F. Chen, Z. Wang, and X. Hu. 2007. Chemical compositional characterization of some apple cultivars. Food Chem. 103:88-93. 